\title{
Microsatellites within genes and ESTs of the Pacific oyster Crassostrea gigas and their transferability in five other Crassostrea species
}

\author{
Qi Li* \\ Fisheries College \\ Ocean University of China \\ Qingdao 266003 \\ P.R. China \\ Tel: 8653282031622 \\ Fax: 8653282032773 \\ E-mail: qili66@ouc.edu.cn \\ Shikai Liu \\ Fisheries College \\ Ocean University of China \\ Qingdao 266003 \\ P.R. China \\ Lingfeng Kong \\ Fisheries College \\ Ocean University of China \\ Qingdao 266003 \\ P.R. China
}

Financial support: National High Technology Research and Development Program (2006AA10A409) and Ministry of Education of China (707041).

Keywords: indwelling medical devices, infections, surface attachment.

Abbreviations: AFLP: amplified fragment length polymorphism
EST: expressed sequence tags
$\mathrm{H}_{\mathrm{e}}$ : expected heterozygosity
$\mathrm{H}_{\mathrm{o}}$ : observed heterozygosity
HWE: Hardy-Weinberg equilibrium
PCR: polymerase chain reaction
SSR: simple sequence repeat

We developed 15 novel polymorphic microsatellites for the Pacific oyster Crassostrea gigas by screening genes and expressed sequence tags (ESTs) found in GenBank. The number of alleles per locus ranged from two to 24 with an average of 8.7 , and the values of observed heterozygosity $\left(H_{0}\right)$ and expected heterozygosity $\left(H_{\mathrm{e}}\right)$ ranged from 0.026 to 0.750 and from 0.120 to 0.947 , respectively. No significant pairwise linkage disequilibrium was detected among loci and eight loci conformed to Hardy-Weinberg equilibrium. Transferability of the markers was examined on five other Crassostrea species and all the markers were amplified successfully in at least one species. These new microsatellites should be useful for population genetics, parentage analysis and genome mapping studies of $C$. gigas and closely related species. The nine markers identified from known genes are expected to be especially valuable for comparative mapping as type I markers.

The Pacific oyster, Crassostrea gigas, naturally distributed in Japan, China and Korea, has become a worldwide aquaculture species because of its fast growth rate, high disease resistance and adaptability to different environments. It has had the highest worldwide production of any cultured aquatic species since 1993; in 2006, world production of this species was 4.6 million metric tons (Food and Agriculture Organization, 2008). Still, oysters are in an early stage of domestication. To improve the increasingly valuable Pacific oyster industry, genetic improvement programs have been initiated in several countries (Langdon et al. 2003), and to date two genetic linkage maps that would facilitate marker-assisted selection, quantitative trait locus (QTL) mapping, and functional genomic research have been developed using amplified fragment length polymorphism (AFLP) (Li and Guo, 2004), and microsatellite markers (Hubert and Hedgecock, 2004). However, the AFLP maps are poorly transferable, and the microsatellite map is only moderately. There is a great need for developing codominant markers in the Pacific oyster.

Microsatellites, or simple sequence repeats (SSRs), are

*Corresponding author 
Table 1. Characterization of 15 novel polymorphic microsatellites within genes and ESTs for the Pacific oyster Crassostrea gigas.

\begin{tabular}{|c|c|c|c|c|c|c|c|c|c|c|}
\hline Locus & Repeats & Primer sequence (5'-3') & $T$ & $\begin{array}{c}N_{0} \text { (size } \\
\text { range bp) }\end{array}$ & Gene identiby & $\begin{array}{c}\text { Locationin } \\
\text { the gene }\end{array}$ & H. & H. & $P$ & $\begin{array}{l}\text { Accession } \\
\text { na. }\end{array}$ \\
\hline \multirow[t]{2}{*}{ CGGO01 } & $(\mathrm{AT})_{6}$ & F: GTGCCTCCTCTATGTGGG & 60 & $3(320-340)$ & Alpha amplase A & 1st intron & 0,050 & 0.441 & $0.000^{*}$ & $\mathrm{AF} 32068$ \\
\hline & & R:GGATCGCTGTTTCACTCG & & & & & & & & \\
\hline \multirow[t]{2}{*}{ CGGOC2 } & $(A G) ;$ & F: CAAACAAGGTATCATCCG & 54 & $16(204-244)$ & $S$ ribos ome RHA & NTS & 0256 & 0.888 & $0.000^{*}$ & AY765366 \\
\hline & & R:AATAATAGCAGCTTCCATC & & & & & & & & \\
\hline \multirow[t]{2}{*}{ CGGOOB } & $(A G)_{16}$ & F:GGAGGACAAAGAGGAGGT & 58 & $9(405-413)$ & Metallothionein & lst introm & 0.525 & 0.812 & 0.001 & AJ242657 \\
\hline & & R: CCAGTCCCGCATGTCTAG & & & & & & & & \\
\hline \multirow[t]{2}{*}{ CGGO04 } & $(G A) 12$ & F: GAGTATTGAGGAGACGGAC & 56 & $13(631-639)$ & Activin-like type 1 receptor & lst intron & 0.105 & 0.903 & $0.000^{*}$ & AJ309316 \\
\hline & & R: GACAGTTCATCAGGTGCTTC & & & & & & & & \\
\hline \multirow[t]{2}{*}{ CGGOOS } & $(\mathrm{GA})_{26}$ & F: AGCACGGCAGAGGATAGG & 56 & $19(361-415)$ & Clitinase-like protein 1 & 3rd introm & 0.180 & 0.939 & $0.00^{*}$ & A 9971241 \\
\hline & & R: ACTATTCGGCGGGTCTCA & & & & & & & & \\
\hline \multirow[t]{2}{*}{ CGG006 } & $(\mathrm{AG}) 18$ & F: AGCCTTGAATAATCGGTC & 56 & $7(430-448)$ & Metallothionein 2 & 1st intron & 0.750 & 0.594 & 0.374 & AJ297818 \\
\hline & & R: ATTTACACCCGTCACCAC & & & & & & & & \\
\hline \multirow[t]{2}{*}{ CGGOO? } & $(\mathrm{GA})_{22}$ & F: ATTGTTTCTGTCTTCGTC & 50 & $3(345-349)$ & LPS-binding protein & $3 \mathrm{UTR}$ & 0025 & 0.285 & $0.000^{*}$ & AY 165040 \\
\hline & & R: TCGTACAAGAATAAAGGAT & & & & & & & & \\
\hline \multirow[t]{2}{*}{ CGGO0B } & $(\mathrm{AG}) 20$ & F: TCTCCTCTACCCCGACAG & 56 & $24(176-254)$ & Inon regulatory protein 1-like protein & 1st introm & 0.650 & 0.947 & $0.000^{*}$ & AJS79915 \\
\hline & & R:GTGATGAACAAACCACCAAC & & & & & & & & \\
\hline \multirow[t]{2}{*}{ CGGOOA } & $(\mathrm{AT}) \mathrm{s}$ & F:CCTTAACTGCACTGGTCCC & 60 & $2(154-160)$ & Heat shock protein 68 & $3 \mathrm{UTR}$ & 0.083 & 0.178 & 0.021 & $\mathrm{AB} 122062$ \\
\hline & & R: CGTGCAATGATAAATGATGC & & & & & & & & \\
\hline \multirow[t]{2}{*}{ CGEO2? } & $(A G)_{s}$ & F:GCCGCCTTTCAGACTTTC & 54 & $8(278-298)$ & Unhaown & Unlnown & 0675 & 0.761 & 0.274 & ES789161 \\
\hline & & R: GATGGGACAAACAACGACA & & & & & & & & \\
\hline \multirow[t]{2}{*}{ CGEO28 } & (CT) & F:CATCTTGTTGTAACCCACG & 54 & $3(246-254)$ & Unhrowm & Unknown & 0.125 & 0.120 & 1.000 & DV736587 \\
\hline & & R: GCTTCCCTTTAA TGATTCTC & & & & & & & & \\
\hline \multirow[t]{2}{*}{ CGEOBO } & $(\mathrm{AC})_{s}$ & F: TGCTGCCTGTGGAATGTT & 52 & $2(193-195)$ & Unharown & Unknown & 0375 & 0.392 & 1.000 & $\mathrm{BQ} 427330$ \\
\hline & & R:TTGTGTTGAGTCGCAAGAGT & & & & & & & & \\
\hline \multirow[t]{2}{*}{ CGEOB1 } & $(\mathrm{CT}) ;$ & F: GATCATTGAAAGAAAGTC & 48 & $3(116-124)$ & Unharown & Unlnown & 0359 & 0.403 & 0.295 & $\mathrm{BQ} 426470$ \\
\hline & & R: CATTGTTGAATAGGTTGT & & & & & & & & \\
\hline \multirow[t]{2}{*}{ CGEOB2 } & $(\mathrm{AG})$ & F: TCGTTGAAGGTGACAAGT & 55 & $15(140-172)$ & Unlarown & Unknown & 0.667 & 0.899 & $0.000^{*}$ & CX068987 \\
\hline & & R: AACCGAACCATTTACATC & & & & & & & & \\
\hline \multirow[t]{2}{*}{ CGEO33 } & $(\mathrm{TA}) \mathrm{s}$ & F:AGTGCCTTCCTATTGTTG & 55 & $4(174182)$ & Unhaown & Unlnown & 0263 & 0.411 & 0.411 & $\mathrm{BQ} 426500$ \\
\hline & & R: GGCGATGATAATGATGAC & & & & & & & & \\
\hline
\end{tabular}

$T_{\mathrm{a}}$, optimal armealing temperature $\left({ }^{\circ} \mathrm{C}\right) ; N_{\mathrm{a}}$, number of alleles; $H_{\mathrm{a}}$, ob semed heterczygosity; $H_{\mathrm{s}}$ expected heterozfgos ity; $P$, exact $P$ vabue for Hard $y$-Weirberg equilib rim test; $*$, statistically sigrificant after Borfenori comection $(P \leq 001 / 15)$.

extremely useful markers for genetic linkage mapping because of their high polymorphism, abundance, codominance and small length, which facilitates genotyping using polymerase chain reaction (PCR) (Liu et al.1999; Wang et al. 2007). For C. gigas, numerous microsatellites have been developed recently ( $\mathrm{Li}$ et al. 2003). But, the pace of development has been limited by the time-consuming and labor intensive requirement to construct, enrich and sequence genomic libraries (Edwards et al.1996). Recently, identification of microsatellites from expressed sequences has been extensively used as an alternative strategy. In addition to requiring less time and money to develop, expressed sequence tags (EST)-derived microsatellites have a number of intrinsic advantages. They tend to be more widely transferable between species, and even genera (Bouck and Vision, 2007). More importantly, because they represent genes, they serve as type I markers, which are more valuable for comparative gene mapping (Liu et al. 1999). To date, a large number of EST-SSRs have been successfully developed from public sequence databases in several aquatic animals, including fish (Serapion et al. 2004), shrimp (Perez et al. 2005), sea urchin (Kong and Li,
2008) and molluscs such as the Eastern oyster (Wang and Guo, 2007) and Pacific oyster ( $\mathrm{Yu}$ and Li, 2007; Yu and Li, 2008; Wang et al. 2008; Sauvage et al. 2009). Although detection of microsatellites within ESTs generates potential type I markers (Serapion et al. 2004), usually only a small proportion of EST-SSRs shows high identity to previously annotated genes in aquatic species. For example, 16 of 65 (24.6\%) showed high identity to annotated genes and was confirmed as type I markers in Atlantic salmon, and similar results have been reported for Eastern oyster (32.1\%) and Pacific oyster (37.5\%) (Ng et al. 2005; Wang and Guo, 2007; $\mathrm{Yu}$ and $\mathrm{Li}, 2008$ ). In contrast, microsatellites identified from known genes are all type I markers. The identification of specific SSRs in known genes permits not only the location of the genes in linkage maps, but also the unraveling of the biological significance of SSR distribution, expansion, and contraction on the function of the genes themselves ( $\mathrm{Li}$ et al. 2004). In the present study we report the identification of microsatellites within all known genes and ESTs from C. gigas, as well as their characterization and cross-species amplification in five other commercially important Crassostrea species. 


\section{MATERIALS AND METHODS}

All the Pacific oyster gene sequences and 1168 EST sequences were downloaded from GenBank (NCBI, http://www.ncbi.nlm.nih.gov/sites/entrez). The SSRHUNTER program ( $\mathrm{Li}$ and Wan, 2005) was used to search for SSRs. The criteria used in SSRHUNTER to identify SSRs were as follows: five repeats for di-, tri- and tetranucleotide repeats. EST sequences containing microsatellites were assembled using SeqMan II sequence assembly software (DNASTAR Inc. Madison, USA) for clustering analysis. Sequences containing SSRs were annotated using BLAST software. Primers flanking microsatellites were designed using the Primer Premier 5.0 program.

To evaluate polymorphism, 40 individuals of C. gigas collected from coastal waters in Hiroshima, Japan, were used. Genomic DNA was extracted from adductor muscle by standard proteinase $\mathrm{K}$ digestion, phenol-chloroform extraction, and DNA precipitation. PCRs were performed in $10-\mu \mathrm{L}$ volumes containing $0.25 \mathrm{U}$ Taq DNA polymerase (Takara Inc.), 1 x PCR buffer, $0.2 \mathrm{mM}$ dNTP mix, $1 \mu \mathrm{M}$ of each primer set, $1.5 \mathrm{mM} \mathrm{MgCl} 2$ and about 100 ng template DNA. PCR was performed on a GeneAmp 9700 PCR System (Applied Biosystems) as follows: $3 \mathrm{~min}$ at $94^{\circ} \mathrm{C} ; 35$ cycles of $1 \mathrm{~min}$ at $94^{\circ} \mathrm{C}$, annealing (Table 1 , annealing temperatures) for $1 \mathrm{~min}, 72^{\circ} \mathrm{C}$ for $1 \mathrm{~min}$ per cycle; followed by $5 \mathrm{~min}$ at $72^{\circ} \mathrm{C}$. Amplification products were resolved via
$6 \%$ denaturing polyacrylamide gel, and visualized by silver-staining. A 10-bp DNA ladder (Invitrogen Inc.) was used as a reference marker for allele size determination. The number of alleles $\left(N_{a}\right)$, expected heterozygosity $\left(H_{\mathrm{e}}\right)$ and observed heterozygosity $\left(H_{0}\right)$ were calculated using Microsatellite Analyser software (Dieringer and Schlötterer, 2003). Tests for linkage disequilibrium and deviations from Hardy-Weinberg equilibrium (HWE) were performed using the GENEPOP program. Significant levels were calculated per locus using sequential Bonferroni method (Rice, 1989).

\section{RESULTS AND DISCUSSION}

A total of 327 gene sequences and 1168 EST sequences were screened for microsatellite repeats, from which 21 gene sequences and 37 EST sequences harbored microsatellite-type repeats. From the sequences containing microsatellites, 41 primer pairs were designed for microsatellite marker optimization. Of the 41 primer pairs, 12 were not easily amplified, 14 were monomorphic (Appendix A) and 15 produced polymorphic profiles of the expected size. All these loci are different from the published EST-SSRs ( $\mathrm{Yu}$ and Li, 2007; $\mathrm{Yu}$ and $\mathrm{Li}, 2008$; Wang et al. 2008; Sauvage et al. 2009). Characterizations of these polymorphic loci are summarized in Table 1 . The numbers of alleles ranged from 2 to 24 with an average of 8.7 alleles per locus. The observed and expected heterozygosities ranged from 0.026 to 0.750 and from

Table 2. Cross-species amplification of 15 microsatellites from $C$. gigas in five other Crassostrea species including $C$. plicatula, C. hongkongensis, $C$. ariakensis, C. nippona and C. sikamea.

\begin{tabular}{|c|c|c|c|c|c|}
\hline \multirow{2}{*}{ Locus } & C plicatula & C hongkongensis & C ariakensis & C nippona & C sikamea \\
\cline { 2 - 6 } & $(n=30)$ & $(n=30)$ & $(n=30)$ & $(n=30)$ & $(n=30)$ \\
\hline CGG001 & $5(300-316)$ & - & - & - & $6(310-332)$ \\
\hline CGG002 & $7(206-238)$ & $6(214236)$ & $7(216-236)$ & $5(210-226)$ & $5(216-234)$ \\
\hline CGG003 & $7(405-421)$ & $1(330)$ & $1(330)$ & $1(310)$ & $5(407-421)$ \\
\hline CGG004 & - & $6(631-651)$ & $3(641-651)$ & $3(639-643)$ & $4(628-641)$ \\
\hline CGG005 & $8(381-399)$ & $6(379-397)$ & $5(381-399)$ & $8(381-397)$ & $3(387-395)$ \\
\hline CGG006 & $3(436-446)$ & - & - & $1(436)$ & $4(434446)$ \\
\hline CGG007 & $3(174180)$ & $3(184188)$ & $1(186)$ & $1(186)$ & $1(216)$ \\
\hline CGG008 & $14(190-240)$ & $2(162-172)$ & $1(172)$ & $2(330-336)$ & $7(196-236)$ \\
\hline CGG009 & $4(150-160)$ & - & - & - & - \\
\hline CGE027 & $5(282-294)$ & $3(288-298)$ & $2(294298)$ & $3(288-298)$ & $2(276-282)$ \\
\hline CGE028 & $1(248)$ & $4(246-254)$ & $3(248-254)$ & $2(248-254)$ & $2(248-254)$ \\
\hline CGE030 & $1(195)$ & $2(195-197)$ & $2(195-197)$ & $1(195)$ & $2(189-195)$ \\
\hline CGE031 & $3(116-120)$ & $2(118-122)$ & $3(116-122)$ & $2(116-118)$ & $5(114124)$ \\
\hline CGE032 & $6(154168)$ & $3(150-156)$ & - & $2(156-158)$ & $4(166-174)$ \\
\hline CGE033 & $3(178-182)$ & $8(174194)$ & $4(176-184)$ & - & $3(184190)$ \\
\hline
\end{tabular}

Numbers of alleles and allele size range (in parentheses); $n$, number of samples. 
0.120 to 0.947 , respectively. No significant pairwise linkage disequilibrium was found among loci. Seven of the 15 microsatellites significantly deviated from the HWE after correction for multiple tests, and all of them showed heterozygote deficiency. We used MICRO-CHECKER (Van Oosterhout et al. 2004) to estimate the most probable cause for departures from HWE. The MICRO-CHECKER analysis suggested there were no indications for scoring error due to stuttering or for large allele dropout. All the seven loci were prone to null alleles $(P<0.01)$. In fact, null alleles are very common in the Pacific oyster $(\mathrm{Li}$ et al. 2003; Hedgecock et al. 2004); due to extremely high levels of DNA sequence variation.

Among the 15 polymorphic markers, nine were identified from known genes, and the other six from ESTs. GenBank (BLASTX) searches indicated that the six SSR-bearing ESTs had no significant matches to genes of known functions at $\mathrm{E}$ values less than $10^{-4}$. The nine microsatellites derived from known genes are all type I markers. Of them, six were located in introns, two (CGG007 and CGG009) in the $3^{\prime}$ untranslated region ( $3^{\prime} \mathrm{UTR}$ ), and one (CGG002) in the non-transcribed spacer (NTS) of 5S ribosome RNA gene (Table 1). Goldstein and Schlötterer (1999) suggest that null alleles in EST-derived SSRs are usually lower than in genomic SSRs due to lower mutation at spicing sites. The fact that all the microsatellites from known genes are located at non-coding sequences might be responsible for high frequency of null alleles ( 7 of 15 or $46.7 \%$ ) detected in this study.

Cross-species amplification was examined in five other Crassostrea species, including $C$. plicatula, $C$. hongkongensis, C. ariakensis, C. nippona and C. sikamea, which were collected from their typical habitats. $C$. plicatula and C. hongkongensis were collected from Fujian and Guangxi provinces in China, respectively; $C$. ariakensis and C. nippona were sampled from the Sea of Ariake and Okatsu Bay, Japan; C. sikamea which originated from Japan were collected from Newport, Oregon, USA. Thirty individuals of each species were used for the examination of the transferability of genic microsatellites. All the primer sets amplified successfully at least one species, with $C$. plicatula and C. sikamea sharing 14 primer pairs, $C$. hongkongensis and C. nippona 12 , and C. ariakensis 11, indicating the high rate of transferability across Crassostrea species (Table 2).

In summary, these genic SSR markers showed adequate level of polymorphism and high rate of transportability. Thus, they can be used as molecular markers for population genetics, pedigree analysis, and genome mapping studies not only in the Pacific oyster but also in related species. The ones located in genes, as type I markers, are expected to be especially useful for mapping these genes in linkage maps and comparative mapping.

\section{REFERENCES}

BOUCK, Amy and VISION, Todd. The molecular ecologist's guide to expressed sequence tags. Molecular Ecology, November 2007, vol. 16, no. 5, p. 907-924.

DIERINGER, Daniel and SCHLÖTTERER, Christian. MICROSATELLITE ANALYZER (msa): a platform independent analysis tool for large microsatellite data sets. Molecular Ecology Notes, March 2003, vol. 3, no. 1, p. 167-169.

EDWARDS, K.J.; BARKER, J.H.A.; DALY, A.; JONES, C. and KARP, A. Microsatellite libraries enriched for several microsatellite sequences in plants. BioTechniques, May 1996, vol. 20, no. 5, p. 758-760.

FOOD and AGRICULTURE ORGANIZATION. World aquaculture production of fish, crustaceans, molluscs, etc., by principal species. Yearbooks of Fishery Statistics, 2008. Available from Internet: ftp://ftp.fao.org/fi/stat/summary/default.htm.

GOLDSTEIN, D.B. and SCHLÖTTERER, C. Microsatellites: Evolution and applications. Oxford, Oxford University Press, 1999. 368 p. ISBN 0-19-850408$\mathrm{X}$.

HEDGECOCK, Dennis; LI, Gang; HUBERT, Sophie; BUCKLIN, Katherine and RIBES, Vanessa. Widespread null alleles and poor cross-species amplification of microsatellite DNA loci cloned from the Pacific oyster, Crassostrea gigas. Journal of Shellfish Research, August 2004, vol. 23, no. 2, p. 379-385.

HUBERT, Sophie and HEDGECOCK, Dennis. Linkage maps of microsatellite DNA markers for the Pacific oyster Crassostrea gigas. Genetics, September 2004, vol. 168, no. 1, p. 351-362.

KONG, Lingfeng and LI, Qi. Development of expressed sequence tag-derived microsatellite markers for the sea urchin Hemicentrotus pulcherrimus. Molecular Ecology Resources, January 2008, vol. 8, no. 1, p. 152-154.

LANGDON, Chris; EVANS, Ford; JACOBSON, Dave and BLOUIN, Michael. Yields of cultured Pacific oysters Crassostrea gigas Thunberg improved after one generation of selection. Aquaculture, April 2003, vol. 220, no. 1-4, p. 227-244.

LI, Gang; HUBERT, Sophie; BUCKLIN, Katherine; RIBES, Vanessa and HEDGECOCK, Dennis. Characterization of 79 microsatellite DNA markers in the Pacific oyster Crassostrea gigas. Molecular Ecology Notes, June 2003, vol. 3, no. 2, p. 228-232.

LI, Li and GUO, Ximing. AFLP-based genetic linkage maps of the Pacific oyster Crassostrea gigas Thunberg. 
Marine Biotechnology, February 2004, vol. 6, no. 1, p. 2636.

LI, Qiang and WAN, Jian-Min. SSRHUNTER: Development of a local searching software for SSR sites. Yichuan, September 2005, vol. 27, no. 5, p. 808-810.

LI, You-Chun; KOROL, Abraham B.; FAHIMA, Tzion and NEVO, Eviatar. Microsatellites within genes: structure, function, and evolution. Molecular Biology and Evolution, June 2004, vol. 21, no. 6, p. 991-1007.

LIU, Zhanjian; TAN, Guo; LI, Ping and DUNHAM, Rex A. Transcribed dinucleotide microsatellites and their associated genes from channel catfish Ictalurus punctatus. Biochemical and Biophysical Research Communications, May 1999, vol. 259, no. 1, p. 190-194.

NG, Siemon H.S.; CHANG, Alan; BROWN, Gordon D.; KOOP, Ben F. and DAVIDSON, William S. Type I microsatellite markers from Atlantic salmon (Salmo salar) expressed sequence tags. Molecular Ecology Notes, December 2005, vol. 5, no. 4, p. 762-766.

PEREZ, Franklin; ORTIZ, Juan; ZHINAULA, Mariuxi; GONZABAY, Cesar; CALDERON, Jorge and VOLCKAERT, Filip A.M.J. Development of EST-SSR markers by data mining in three species of shrimp: Litopenaeus vannamei, Litopenaeus stylirostris, and Trachypenaeus birdy. Marine Biotechnology, October 2005, vol. 7, no. 5, p. 554-569.

RICE, W.R. Analyzing tables of statistical tests. Evolution, January 1989, vol. 43, no. 1, p. 223-225.

SAUVAGE, C.; BOUDRY, P. and LAPÈGUE, S. Identification and characterization of 18 novel polymorphic microsatellite makers derived from expressed sequence tags in the Pacific oyster Crassostrea gigas. Molecular Ecology Resources, January 2009, vol. 9, no. 3, p. 853-855.

SERAPION, Jerry; KUCUKTAS, Huseyin; FENG, Jiniang and LIU, Zhanjiang. Bioinformatic mining of type I microsatellites from expressed sequence tags of channel catfish (Ictalurus punctatus). Marine Biotechnology, JulyAugust 2004, vol. 6, no. 4, p. 364-377.

VAN OOSTERHOUT, Cock; HUTCHINSON, William F.; WILLS, Derek P.M. and SHIPLEY, Peter. MICROCHECKER: software for identifying and correcting genotyping errors in microsatellite data. Molecular Ecology Notes, September 2004, vol. 4, no. 3, p. 535-538.

WANG, Chuan Tang; YANG, Xin Dao; CHEN, Dian Xu; YU, Shan Lin; LIU, Guang Zhen; TANG, Yue Yi and XU, Jian Zhi. Isolation of simple sequence repeats from groundnut. Electronic Journal of Biotechnology, July 2007, vol. 10, no. 3, p. 474-480.
WANG, Yongping and GUO, Ximing. Development and characterization of EST-SSR markers in the Eastern oyster Crassostrea virginica. Marine Biotechnology, August 2007, vol. 9, no. 4, p. 500-511.

WANG, Y.; REN, R. and YU, Z. Bioinformatic mining of EST-SSR loci in the Pacific oyster, Crassostrea gigas. Animal Genetics, June 2008, vol. 39, no. 3, p. 287-289.

YU, Hong and LI, Qi. EST-SSR markers from the Pacific oyster, Crassostrea gigas. Molecular Ecology Notes, September 2007, vol. 7, no. 5, p. 860-862.

YU, Hong and LI, Qi. Exploiting EST databases for the development and characterization of EST-SSRs in the Pacific oyster (Crassostrea gigas). Journal of Heredity, March 2008, vol. 99, no. 2, p. 208-214. 


\section{APPENDIX}

Appendix A. Primer sequences, repeat types and annealing temperatures for 26 unamplified and monomorphic microsatellite loci in this study.

\begin{tabular}{|c|c|c|c|c|c|}
\hline Locus & Repeats & Primer sequence (5'-3') & $T_{a}$ & Amplification & Accession no. \\
\hline \multirow[t]{2}{*}{ Cgiyll } & $(A G)_{s}$ & F: CACGAAGGGACCCAAAGA & 56 & Unamplified & AY 551097 \\
\hline & & R: GGGACAATGCCAGTCACTAAA & & & \\
\hline \multirow[t]{2}{*}{$\mathrm{C}_{\text {giyl2 }}$} & $(\mathrm{TAG})_{s}$ & F: TGGTGCCGTTGGATTTGA & 54 & Unamplified & AB262086 \\
\hline & & R: TCACGCTTCCCCATTCAGA & & & \\
\hline \multirow[t]{2}{*}{$\mathrm{CgETl}$} & $(\mathrm{CAG})_{s}$ & F: GTCCCCATCATTACCTCAA & 54 & Monomorphic & ES789767 \\
\hline & & R: CTG TATTCATTTCGTTCCCTA & & & \\
\hline \multirow[t]{2}{*}{$\mathrm{CgET2}$} & $(\mathrm{TG})_{s}$ & F: TTTCTCACGGATAACGACC & 54 & Unamplified & ES789749 \\
\hline & & R: GCAAACAATCAGGCGATG & & & \\
\hline \multirow[t]{2}{*}{$\mathrm{CgET3}$} & $(\mathrm{GA})_{s}$ & F: GACTCAAGGTCGCCAACG & 58 & Monomorphic & ES789722 \\
\hline & & R: TCTCTGAGCCTCTGTTCCAT & & & \\
\hline \multirow[t]{2}{*}{$\mathrm{CgET4}$} & $(\mathrm{CA})_{s}$ & F: CACAAACATCGGTAAAGG & 54 & Monomorphic & ES789663 \\
\hline & & R: GTTGCCAGGATAGTTCTTC & & & \\
\hline \multirow[t]{2}{*}{$\mathrm{CgETS}_{\mathrm{gE}}$} & (GTA ג & F: AGACGATAACGACCACGAC & 56 & Monomorplic & ES789514 \\
\hline & & R: GACTATGGCATCCACCCT & & & \\
\hline \multirow[t]{2}{*}{$\mathrm{CgET6}$} & $(\mathrm{CCG})_{s}$ & F: AAGTTGGTGGAGGAGCAG & 56 & Monomorphic & ES789479 \\
\hline & & R:AAGGTCCGATATTTGAAGC & & & \\
\hline \multirow[t]{2}{*}{$\mathrm{CgET} 8$} & $(G)_{s}$ & F: GGGGAGGGGAAAGAAAAC & 52 & Unamplified & ES789233 \\
\hline & & R: CGACTTGACACGGGAATGA & & & \\
\hline \multirow[t]{2}{*}{ CgET9 } & $(\mathrm{TC})_{s}$ & F: GGGGAGGGGAAAGAAAAC & 52 & Unamplified & ES789175 \\
\hline & & R: CGACTTGACACGGGAATGA & & & \\
\hline \multirow[t]{2}{*}{$\mathrm{CgET}_{\mathrm{gE}}$} & $(A T G)_{s}$ & F: TG TCCTACGGATTCAAGATT & 54 & Unamplified & ES789168 \\
\hline & & R: CCATAGACTGGATAGCACCT & & & \\
\hline \multirow[t]{2}{*}{$\mathrm{CgETl2}$} & $\left(\mathrm{GT}_{s}\right.$ & F: AGGACGG TCAGTTCTTGT & 56 & Monomorphic & DV736792 \\
\hline & & R: TTGGTGTAATGTTGTCCC & & & \\
\hline \multirow[t]{2}{*}{$\mathrm{CgETl} 6$} & $(A T)_{s}$ & F: GACTTCACCAAGAAATACG & 52 & Monomorphic & CX068904 \\
\hline & & R: TCACTATCGG TTACAGCAC & & & \\
\hline \multirow[t]{2}{*}{$\mathrm{CgETl7}$} & $(G)_{s}$ & F: CTGCCTTCGGTGTTCCTT & 58 & Unamplified & CB617346 \\
\hline & & R: CACATAGACGGGCTGAGAAC & & & \\
\hline \multirow[t]{2}{*}{$\mathrm{CgETl} 8$} & $(\mathrm{AGA})_{s}$ & F: ACATGCAACTACAACCCCC & 56 & Monomorphic & AJ 565768 \\
\hline & & R: TGGATGCCCAATCACAAG & & & \\
\hline \multirow[t]{2}{*}{ CgETl9 } & $(\mathrm{AC})_{s}$ & F: TCAGTCTGGTGATTTCGTG & 52 & Unamplified & $\mathrm{BQ} 427090$ \\
\hline & & R: AGTGGCGTGACTTCCTGT & & & \\
\hline \multirow[t]{2}{*}{$\mathrm{CgET} 20$} & $(\mathrm{TA})_{s}$ & F: TTCCATCTTCAAGTTCGG & 52 & Unamplified & $\mathrm{BQ} 426771$ \\
\hline & & R: GAGCACATATTTTGCGTTA & & & \\
\hline \multirow[t]{2}{*}{$\mathrm{CgET} 23$} & $(A G)_{6}$ & F: CAGATTTGATTGTAGTTC & 54 & Monomorplic & CX739659 \\
\hline & & R: CAAGATTGAGCAGAGTTA & & & \\
\hline \multirow[t]{2}{*}{$\mathrm{CgET} 24$} & $(\mathrm{CA})_{s}$ & F: CAGACTACCAACCCACCT & 56 & Unamplified & $\mathrm{BQ} 427097$ \\
\hline & & R: CCACAGAATGACGCAAGT & & & \\
\hline \multirow[t]{2}{*}{ CgET25 } & $(\mathrm{TC})_{s}$ & F: TCAACTACAAAATGCTCCTC & 46 & Unamplified & $\mathrm{BQ426985}$ \\
\hline & & R: ATACGGTGGTGACGATTA & & & \\
\hline $\mathrm{CgET} 27$ & $(\mathrm{TG})_{s}$ & F: GTTGAGACA TTAGGGAGAT & 55 & Monomorphic & $\mathrm{BQ426493}$ \\
\hline & & R: TGTGTAAACAGAGGGTAGTG & & & \\
\hline CgET28 & $(\mathrm{AG})_{s}$ & F: GAGTATGAGGCAGCAGAG & 54 & Monomorphic & $\mathrm{BQ426346}$ \\
\hline & & R:GTATCGTTTGCTTTGTGC & & & \\
\hline $\mathrm{CgET} 29$ & $(\mathrm{GAA}) \mathrm{s}$ & F: AGATGCTGA TGGGTTTAT & 55 & Monomorphic & CK172355 \\
\hline & & R: CCCTG TTTCACTCTTTTC & & & \\
\hline $\mathrm{CgET} 30$ & $(A G)_{s}$ & F: ATACCATTCATACAACCGAT & 55 & Monomorphic & $\mathrm{CK} 172332$ \\
\hline & & R: TTCAACTACAAAATGCTCCT & & & \\
\hline CgET31 & $(\mathrm{CT})_{6}$ & F: TTGGACTATCACATCTCA & 58 & Monomorphic & DV736587 \\
\hline & & R: ACAGTTTATTACCTACTTCTA & & & \\
\hline $\mathrm{CgET} 32$ & $(\mathrm{CAA})_{6}$ & F: AGGCAGAGGCAACAAACT & 55 & Unamplified & DV736339 \\
\hline & & R: CGTGATGAACAATAGCGAAA & & & \\
\hline
\end{tabular}

$T_{\mathrm{a}}$, optimal annealing temperature $\left({ }^{\circ} \mathrm{C}\right)$. 